\title{
GROWTH PERFORMANCE AND IMMUNE RESPONSES OF LAMBS AS AFFECTED BY DIETARY SUPPLEMENTATION OF DIFFERENT SELENIUM SOURCES
}

\author{
G. M. A. Solouma ${ }^{1}$, G. A. Abd El-Hafiz ${ }^{2}$, A. Y. Kassab ${ }^{3}$ and A. S. Ali ${ }^{1}$ \\ 1- Department of Animal Production, Faculty of Agriculture, Sohag University, Egypt, 2- Department of \\ Animal Production, Faculty of Agriculture, Assiut University, 3-Department of Animal Production, Faculty \\ of Agriculture, New Valley Branch, Assiut University
}

\section{SUMMARY}

The aim of the study was to evaluate the growth performance and antioxidant status as well as immune responses as affected by supplementation of different selenium (Se) sources in the ration of lambs. This experiment was carried out at the Animal Production Experimental Farm, Faculty of Agriculture, Sohag University, Sohag. Twenty-four healthy Sohagi lambs of about 7-8 month of age and an average body weight of $24.47 \pm 0.15 \mathrm{~kg}$ were randomly assigned into four dietary treatment groups (6 animals each). The experiment was extended for 25-wk after two weeks as adaptation period. Basal diet was formulated to meet all nutrient requirements except selenium. Lambs in the first group were fed a basal diet as a control (T0), whereas lambs in groups T1, T2, and T3 were fed the basal diet supplemented with $0.1 \mathrm{mg} / \mathrm{kg}$ DM from sodium selenite, vitamin $E$ and selenium and selenized yeast, respectively. Animals were weighed at the beginning of the experimental period and thereafter at monthly intervals (for two consecutive days) before offering the morning feed and water throughout the experimental period to assess their growth rate. Values of total gain, average daily gain and feed conversion were calculated.Three blood samples from three animals in each group were collected before offering the morning feed and water throughout the experimental period from jugular venipuncture at 8.0 a.m. into 10-mL heparinized tubes at days 0,30,60,90,120, and 150 of the experiment. The concentrations of Se in whole blood were determined. The activity of glutathione peroxidase (GSH-Px) was determined in whole blood of lambs and the concentrations of interleukins (IL-1\&IL-2) in blood plasma were analyzed as well. Results indicated that T3, T2 and T1 treatments increased body weight $(B W)$ at the end of experimental period by $24.17 \%, 18.24 \%$ and $8.53 \%$, respectively compared to control group. Also, T3, T2 and T1 treatments increased the daily gain $(D G)$ by $56.28 \%, 43.76 \%$ and $22.81 \%$ respectively in comparison with control group. The feed conversion ratios differed $(P<0.01)$ among treatments. The best values were recorded in T3 followed by T2, while the worst values were recorded in T1 and control groups. Values of blood Se concentrations differed $(P<0.01)$ among groups. The highest value of Se concentration was recorded in T3 followed by T2, T1 and the lowest value was recorded in control group. Moreover, the GSH-Px activities in T3 and T2 were higher $(P<0.01)$ than those in T1 and control groups, but there was no significant difference in the GSH-Px activities between T3 and T2 groups. In addition, data showed that the concentrations of IL-1 and IL-2 in plasma increased in all of the supplemented groups during the period of supplementation. The highest values of plasma IL-1 and IL-2 concentrations were recorded in T3 followed by T2, T1 and the lowest values were recorded in the control group. In conclusion, supplementation of Se in the ration of sheep especially in the form of selenized yeast is highly beneficial for improving the productive performance and physiological responses as a result of positive effect on glutathione peroxidase (GSH-Px) as indicator of antioxidant and interleukins (IL-1\& IL-2) concentrations as indicator of immune responses.

Keywords: Selenium sources, productive performance, glutathione peroxidase, interleukins, lambs

\section{INTRODUCTION}

Sheep and goat provide an economic support to the small livestock farmers in most developing countries. Imbalance in trace minerals may occur in farm animals, especially ruminants, whose intake of minerals depending largely on the forage species and particularly by the Se status of the soils on which they have grown. Selenium (Se) is an important trace element that has a narrow range between deficiency and toxicity in animals. Serious Se deficiency can lead to nutritional muscular dystrophy, but more common are subclinical symptoms such as weak lambs, reduced feed consumption and pregnancy complications (NRC, 2007)

The $\mathrm{Se}$ is essential for proper health, immunity and reproductive functions of animals. It is a component of glutathione peroxidase (GSH-Px) enzyme, which destroys free radicals in the cytoplasm and protects the tissues against oxidative damage (Awad et al., 1994 and Levander et al., 1995). Se is also involved in immune function (McKenzie et al. 1998) and resistance against diseases (Huang and Yang, 2002). Safir et al. (2003) reported that macrophage supplemented with Se increased the release of IL-1 in vitro. However, as far as authors know, there are no previous data available 
in the literature about that whether the activities of interleukins in plasma are enhanced in vivo upon Se supplementation. Also, few studies were undertaken on the effects of different Se sources on growth performance and Se status of sheep.

In most practical way and conveniently the fortifying Se in fertilizers was anticipated to be the best means for supplying the livestock with adequate Se through plant uptake of various Se compounds. Selenium supplements are in two principle forms, inorganic mineral salts, typically sodium selenite or selenite or in organic forms such as Se enriched yeast. Selenium absorption occurs within the small intestine whilst SeMet is absorbed via the methionine transporter system. The absorption of inorganic Se, such as sodium selenite, is less efficient and occurs mainly by passive diffusion (Weiss, 2003). Specifically, research has shown that organic Se is more bioavailable than so in inorganic form like for instance sodium selenite (Cantor et al., 1982). Therefore, organic sources of Se, such as Se-yeast have been explored as an alternative to inorganic supplementation. Additionally, the use of organic Se resulted in less Se being transferred to the environment through feces and more Se is deposited into body tissues and animal products. The dietary concentration and source of Se have been demonstrated to affect antioxidant system and $\mathrm{Se}$ status (Juniper et al., 2009; Vignola et al., 2009 and Petrera et al., 2009). The aim of this study was to evaluate the growth performance of male lambs and on glutathione peroxidase (GSH-Px) as indicator of antioxidant and interleukins (IL-1\& IL-2) concentrations as indicator of immune responses. as affected by supplementation of different selenium sources.

\section{MATERIALS AND METHODS}

This experiment was carried out at the Animal Production Experimental Farm, Faculty of Agriculture, Sohag University, Sohag. It lasted about 25 weeks from February up to July, 2014. All lambs were raised under the same managerial and environmental conditions.

\section{Proximate chemical analysis:}

Chemical analyses for basal diet according to the methods of A.O.A.C. (2000), for dry matter, crude protein, ether extract, crude fiber and ash on dry matter bases were 90.02, 16.53, 3.10, 13.98 and $12.75 \%$, respectively. Also, the concentration value of selenium was $0.088 \mathrm{ppm}$.

\section{Experimental design:}

Twenty-four healthy Sohagi male lambs of about 7-8 month of age and an average body weight (BW) of $24.47 \pm 0.15 \mathrm{~kg}$ were randomly assigned into four dietary treatment groups (six animals each). The experiment was extended for 25 weeks preceded by two weeks as adaptation period. Basal diet was formulated to meet nutrient requirements according to NRC (1985) except Se. Se requirement according to NRC (1985) level of $0.1-0.2 \mathrm{mg} \mathrm{Se} / \mathrm{kg}$ dry matter was recommended for sheep .The basal diet consisted of $30 \%$ wheat straw and $70 \%$ concentrate mixture. Lambs in control group (T0) were fed a basal diet without supplement, whereas lambs in groups T1, T2, and T3 were fed the basal diet supplemented with 0.1 $\mathrm{mg} / \mathrm{kg}$ DM from sodium selenite, vitamin $\mathrm{E}$ and selenium and selenized yeast, respectively. The basal diet was formulated to be adequate in protein, energy, vitamins and mineral for growing lambs phase except for Se content. Lambs were fed individually and water was available ad libitum. Feed intake of each animal was recorded daily during the experimental period to measure the daily DM intake (DMI) and feed conversion ratio (FCR). Animals were weighed at beginning of experimental period and then at monthly intervals (for two consecutive days) in the morning before offering feed and water throughout the experimental period to assess their growth rate. Values of total gain (TG), daily gain (DG) and feed conversion ratio (daily DM intake/ daily gain, g/g) were calculated.

\section{Blood sampling and analysis:}

Blood samples from three animals in each group were collected before offering morning feed and water from the jugular vein at 8.0 a.m. into $10 / \mathrm{mL}$ heparinized tubes at day 0, 30, 60, 90, 120, and 150 of the experiment. Samples of whole blood were stored at $-20^{\circ} \mathrm{C}$ for subsequent specific chemical analysis. Blood plasma samples were then separated by centrifugation at $3000 \mathrm{rpm}$ for 15 minutes. The concentrations of Se in whole blood were determined by atomic absorption spectrometry with a hydride generator system (Norheim and Haugen, 1986). Before analysis, each sample was prepared by oxidative digestion in a mixed solution with concentrated nitric and perchloric acids, using an automated system. All selenium concentrations were calculated as mg / L blood. The activity of GSH-Px was determined in whole blood of lambs with commercial test kits. Method for determination of GSH-Px is based on catalytic oxidation of glutathione as described by Sankari (1985) IL-1 ${ }^{125}$ I radioimmunoassay (RIA) Kits and IL-2 ${ }^{125}$ I RIA Kits were used to assay the concentrations of interleukins in blood plasma. The detection range (DR) of the IL1 kits is $0.125-4.0 \mathrm{ng} / \mathrm{mL}$. The detectable concentration (DC) is less than $0.08 \mathrm{ng} / \mathrm{ml}$ and the inter-assay and intra-assay variation coefficients were $10 \%$ and $8 \%$, respectively. The DR of the IL- 2 kit is $0.2-9.6 \mathrm{ng} / \mathrm{ml}$, the DC is less than $0.1 \mathrm{ng} / \mathrm{mL}$, and inter-assay and intra-assay variation coefficients were $7 \%$ and $8 \%$, respectively.

\section{Statistical analysis:}

Data were statistically analyzed using the General Linear Model (SAS, 2008) one way analysis of variance. All statements of significant difference are 
based on the 0.05 or 0.01 probability levels. Significant differences among treatments, within the experiment were analyzed using L.S.D (Petersen, 1985) for growth rate, feed conversion ratio, blood parameters. The following model was used,

$\mathrm{Y}_{\mathrm{ij}}=\mu+\mathrm{T}_{\mathrm{i}}+\mathrm{E}_{\mathrm{ij}}$

Where,

$\mathrm{Y}_{\mathrm{ij}}=$ Experimental observation. $\mu=$ The overall mean.

$\mathrm{T}_{\mathrm{i}}=$ The effect of dietary treatments, $\mathrm{i}=\mathrm{T} 0, \mathrm{~T} 1, \mathrm{~T} 2$, and $\mathrm{T} 3$

$E_{i j}=$ The errors (Standard Error (S.E) ) related to individual observation.

\section{RESULTS AND DISCUSSION}

\section{Growth performance of lambs:}

Data in Table (1) showed the effect of different selenium sources on body weight (BW), total gain and daily gain (DG). Data revealed that, the final BW was differed $(\mathrm{P}<0.01)$ among treatments. The highest value for $\mathrm{BW}$ was recorded for the selenized yeast (T3) followed by vitamin E and selenium (T2), sodium selenite (T1) and the lowest one was recorded for the control group. The present results indicated that $\mathrm{T} 3, \mathrm{~T} 2$ and $\mathrm{T} 1$ treatments increased $\mathrm{BW}$ at the end of the experimental period by $24.17 \%, 18.24 \%$ and $8.53 \%$, respectively compared to control. Supplementation of Se had a positive effect on the growth performance of the lambs being the best impact with organic Se. Table (1) showed that T3, T2 and $\mathrm{T} 1$ treatments significantly increased the total daily gain (DG) by $56.28 \%, 43.76 \%$ and $22.81 \%$, respectively in comparison with control group. Similar trend among treatments regarding total gain was observed, with the superior value that associated with selenized yeast treatment T3. Kumar et al. (2009) showed that supplementation of organic as well as inorganic Se improved the growth rate of the lambs. Also, organic Se was more effective than inorganic Se. Similar results were obtained in chicken, goats and cow (Wang and $\mathrm{Xu}, 2008$; Yue et al., 2009 and Shi et al., 2011).

In contrast, some investigation results indicated that Se levels or Se source did not influence growth of lambs (Vignola et al. 2009 and Antunović et al., 2014). The discrepancy among the previous studies may be associated with the variation in feedstuffs, breeds or the environmental conditions in each experiment (Ružić-Muslić et al., 2014). Moreover, high Se intake (Lopez et al., 1968) and also in some cases high dietary protein level (Ganther et al., 1966) may increase expired selenium.

Table 1. Effect of different selenium sources on growth performance of lambs during the 150 days of the experimental period

\begin{tabular}{|c|c|c|c|c|}
\hline \multirow{2}{*}{ Items } & \multicolumn{4}{|c|}{ Treatments } \\
\hline & T 0 & T1 & T2 & T3 \\
\hline Initial BW, (kg) & $24.50 \quad \pm 0.35$ & $24.10 \pm 0.69$ & $24.53 \pm 0.23$ & $24.83 \pm 0.25$ \\
\hline Final BW, (kg) & $41.95^{\mathrm{D}} \pm 0.45$ & $45.53^{\mathrm{C}} \pm 0.69$ & $49.60^{\mathrm{B}} \pm 0.23$ & $52.09^{\mathrm{A}} \pm 0.25$ \\
\hline Total gain, (kg) & $17.45^{\mathrm{D}} \pm 0.42$ & $21.43^{\mathrm{C}} \pm 0.14$ & $25.07^{\mathrm{B}} \pm 0.03$ & $27.27^{\mathrm{A}} \pm 0.03$ \\
\hline Daily gain, (g/d) & $116.33^{\mathrm{D}} \pm 2.81$ & $142.83^{\mathrm{C}} \pm 0.96$ & $167.13^{\mathrm{B}} \pm 0.17$ & $181.77^{\mathrm{A}} \pm 0.18$ \\
\hline
\end{tabular}

Control $=$ Without treatment; T1 $=$ Sodium selenite treatment; T2= Vitamin E and Selenium treatment. T3= Selenized yeast treatment . Means and Standard error (S.E) followed by superscript letters different within the same row are significantly different at $\mathrm{P}<0.01$

Intake and feed conversion ratio:

Table (2) showed non significant differences in daily DM intakes among experimental dietary treatments, while daily gain in Table (1) showed significant increase in different treatments. Thus, the feed conversion ratio (daily DM / daily gain, g/g) differed $(\mathrm{P}<0.01)$. The best value was recorded in $\mathrm{T} 3$ followed by $\mathrm{T} 2$, while the worst value was recorded in $\mathrm{T} 1$ and $\mathrm{T} 0$ (control). Improve feed conversion ratio was observed in the Se supplemented rations of lambs (Grace and Knowles, 2002 and Juniper et al., 2009), in cattle (Wichtel et al., 1994), as well as beef cattle (Nicholson et al., 1991). Moreover, in an experiment with rabbits, Hassan et al. (2015) found that, rations supplemented with Se-algae (organic form) significantly improved FCR in comparison with the free form of the supplement. Contrary, Mudgal et al. (2007) reported no difference in feed conversion ratio in buffalo calves supplemented with $0.3 \mathrm{mg} \mathrm{Se} / \mathrm{kg}$ DM. Heider and Bock, (1993) identified Se as a part of cellular glutathione peroxidase, which provided evidence for Se movement in many metabolic processes and subsequently affecting potentially productive performance of animals.

Table 2. Effect of different Se sources on total DM intakes and feed conversion ratio during the experimental period

\begin{tabular}{|c|c|c|c|c|}
\hline \multirow{2}{*}{ Items } & \multicolumn{4}{|c|}{ Treatments } \\
\hline & Control (T0) & T1 & T2 & T3 \\
\hline \multicolumn{5}{|c|}{ Average daily consumption of DM } \\
\hline Daily DM( g) intak & $984.71 \pm 14.57$ & $985.48 \pm 14.6$ & $986.22 \pm 14.64$ & $986.47 \pm 14.68$ \\
\hline \multicolumn{5}{|c|}{ Feed conversion ratio } \\
\hline DM/gain (g/g) & $8.46^{\mathrm{A}} \pm 0.203$ & $6.90^{\mathrm{B}} \pm 0.047$ & $5.90^{\mathrm{C}} \pm 0.006$ & $5.43^{\mathrm{D}} \pm 0.005$ \\
\hline
\end{tabular}

Control= Without treatment; T1 = Sodium selenite treatment; T2= Vitamin E and Selenium treatment. T3= Selenized yeast treatment . Means and Standard error (S.E) followed by superscript letters different within the same row are significantly different at $\mathrm{P}<0.01$ 
Effect of different sources of selenium on blood analysis:

\section{A-Whole-blood Se concentrations}

Data in Table (3) showed that Se concentrations in whole blood were not significantly different among groups at the beginning of the experiment. However, after one month, Se concentrations of whole blood increased gradually until the end of the experiment in all supplemented groups (T1, T2 and T3).

Also, the whole-blood Se concentrations in T3 and $\mathrm{T} 2$ were higher $(\mathrm{P}<0.01)$ than that in $\mathrm{T} 1$ group. Differences among the experimental dietary treatments respecting the Se concentrations of whole blood were statistically significant over 1 to 5 months of sampling. The highest value of Se concentrations was recorded in $\mathrm{T} 3$ followed by $\mathrm{T} 2, \mathrm{~T} 1$ and the lowest value was recorded in control group. Se concentration increased by $176 \%, 141 \%$ and $100 \%$ for T3, T2, T1, respectively compared with control group. Our results are in agreement with those recorded by Gresakova et al. (2013) who found that fourteen weeks feeding diets supplemented with Se either from inorganic or organic source resulted in greater whole blood Se levels compared to animals without supplementation. Additionally, some researchers showed that organic Se was more effective than inorganic Se in increasing blood Se levels in sheep, calves and cows (Van Ryssen et al., 1989 and Nicholson et al., 1991; Knowles et al., 1999 and Gunter et al., 2003). The results of other experiments demonstrated that cattle fed Se-yeast have higher concentrations of $\mathrm{Se}$ in whole blood, serum or plasma and milk those fed inorganic se (Ortman and pehrson, 1997 and Gunter et al., 2003). Similar results were recorded by (Kholif and Kholif, 2008) who found that blood serum Se concentration was greater for buffalos fed $\mathrm{Se}$ enriched yeast than control. Also in cows fed organic Se, blood Se circulating through the mammary gland was removed about 1.5 times more efficiently than in cows receiving inorganic one (Aspila, 1991).

Table 3. Effect of different Se sources on the whole-blood Se concentrations (mg/L) and GSH-Px activity (Units/L) in Lambs

\begin{tabular}{cllll}
\hline \multirow{2}{*}{ Month } & \multicolumn{4}{c}{ Blood Se concentrations } \\
\cline { 2 - 5 } & \multicolumn{1}{c}{ Control } & \multicolumn{1}{c}{ T1 } & \multicolumn{1}{c}{ T2 } & T3 \\
\hline At the beginning & $0.112^{\mathrm{D}} \pm 0.001$ & $0.112^{\mathrm{A}} \pm 0.001$ & $0.111 \pm 0.001$ & $0.111 \pm 0.001$ \\
$\mathbf{1}$ & $0.086^{\mathrm{D}} \pm 0.002$ & $0.184^{\mathrm{C}} \pm 0.003$ & $0.209^{\mathrm{B}} \pm 0.005$ & $0.243^{\mathrm{A}} \pm 0.005$ \\
$\mathbf{2}$ & $0.095^{\mathrm{D}} \pm 0.004$ & $0.207^{\mathrm{C}} \pm 0.011$ & $0.244^{\mathrm{B}} \pm 0.007$ & $0.284^{\mathrm{A}} \pm 0.003$ \\
$\mathbf{3}$ & $0.103^{\mathrm{D}} \pm 0.003$ & $0.220^{\mathrm{C}} \pm 0.011$ & $0.278^{\mathrm{B}} \pm 0.006$ & $0.312^{\mathrm{A}} \pm 0.003$ \\
$\mathbf{4}$ & $0.107^{\mathrm{D}} \pm 0.002$ & $0.240^{\mathrm{C}} \pm 0.008$ & $0.304^{\mathrm{B}} \pm 0.005$ & $0.354^{\mathrm{A}} \pm 0.002$ \\
$\mathbf{5}$ & $0.112^{\mathrm{D}} \pm 0.001$ & $0.266^{\mathrm{C}} \pm 0.008$ & $0.331^{\mathrm{B}} \pm 0.007$ & $0.388^{\mathrm{A}} \pm 0.003$ \\
& & \multicolumn{2}{c}{$\mathbf{B l o o d} \mathbf{G S H}-\mathbf{P x}$ activity } & \\
At the beginning & $245.56^{2} \pm 6.06$ & $243.95 \pm 10.50$ & $244.61 \pm 5.27$ & $238.44 \pm 9.92$ \\
$\mathbf{1}$ & $157.69^{\mathrm{C}} \pm 7.00$ & $284.88^{\mathrm{B}} \pm 8.16$ & $346.30^{\mathrm{A}} \pm 8.22$ & $346.03^{\mathrm{A}} \pm 6.90$ \\
$\mathbf{2}$ & $200.54^{\mathrm{C}} \pm 8.86$ & $337.23^{\mathrm{B}} \pm 11.03$ & $404.81^{\mathrm{A}} \pm 9.33$ & $405.77^{\mathrm{A}} \pm 13.99$ \\
$\mathbf{3}$ & $245.29^{\mathrm{C}} \pm 12.83$ & $381.48^{\mathrm{B}} \pm 12.78$ & $455.42^{\mathrm{A}} \pm 12.90$ & $457.01^{\mathrm{A}} \pm 11.08$ \\
$\mathbf{4}$ & $263.63^{\mathrm{C}} \pm 8.16$ & $413.6^{\mathrm{B}} \pm 12.12$ & $481.76^{\mathrm{A}} \pm 8.75$ & $485.43^{\mathrm{A}} \pm 8.74$ \\
$\mathbf{5}$ & $278.63^{\mathrm{C}} \pm 12.77$ & $431.61^{\mathrm{B}} \pm 9.91$ & $518.19^{\mathrm{A}} \pm 11.67$ & $521.86^{\mathrm{A}} \pm 10.50$ \\
\hline
\end{tabular}

Control= Without treatment; $\mathrm{T} 1=$ Sodium selenite treatment; $\mathrm{T} 2=$ Vitamin E and Selenium treatment. T3= Selenized yeast treatment. Means and Standard error (S.E) followed by different superscript letters within the same row are significantly different at $\mathrm{P}<0.01$.

\section{B-Whole-blood GSH-Px activities:}

The effect of different Se Sources on the wholeblood GSH-Px is presented in Table (3). As expected, GSH-Px activity was not differed significantly among groups at the beginning of the experiment. The activities of GSH-Px in whole blood were higher $(\mathrm{P}<0.01)$ in all of the supplemented groups during the experimental period than in the control. Moreover, the GSH-Px activities in T3 and T2 were higher $(\mathrm{P}<0.01)$ than in $\mathrm{T} 1$ group. However, the differences in the GSH-Px activities between T3 and T2 groups were not significant. When the basal diet was fed only (control T0), the GSH-Px activity was declined sharply from the start of the experiment to one month and then increased steady throughout the experimental period. Our results indicated that selenized yeast and vitamin $\mathrm{E}$ and selenium were more effective than sodium selenite in increasing blood GSH-Px activities in lambs. Similarly, Awadeh et al. (1998) reported that selenized yeast was more effective than sodium selenite in raising the blood GSH-Px activity of cows. Furthermore, Rock et al. (2001) reported that lambs born to ewes fed with selenized yeast had higher concentrations of Se and activities of GSH-Px in blood than lambs born to ewes fed with sodium selenite. Also, results in Table (3) indicated that organic Se sources (selenized yeast and vit. E and Se) were more effectively than inorganic Se source (sodium selenite) in increasing blood Se concentrations and blood GSH-Px activities of lambs. The possible causes are as follows: 
(1) In selenized yeast, the $\mathrm{Se}$ is present predominantly $(94 \pm 5 \%)$ in the form of proteinbound L-selenomethionine. Other Se compounds include, in percentage of total Se as the following: SeCys $(0.5 \%)$, selenocystathionine $(0.5 \%)$, methyl selenocysteine $(0.5 \%)$, g-glutamyl Se Methyl selenocysteine $\quad(0.5 \%), \quad$ Se-adenosylselenohomocysteine (2-5\%), and inorganic Se (1\%). Selenomethionine can be sequestered in the general protein pool as a methionine like compound. Consequently, the half-life of $\mathrm{Se}$ from selenomethionine is greater than the half-lives of other common chemical forms of dietary Se. Swanson et al. (1991) also reported that the half-life of Se in selenomethionine in human was twice that of Se in selenite. Furtherly, Aspila (1991) found that organic Se is more efficient in increasing plasma Se content and Se supplemented animals maintain plasma Se level longer when depleted. He added that about twice as much selenium was eliminated in urine after dosing with inorganic selenium as after dosing with organic selenium.

(2) Se from selenomethionine and selenite was absorbed with similar efficiency (Koenig et al., 1997). However, urinary excretion of Se was greater in lambs fed with selenite compared with those fed with selenomethionine (Ehlig et al., 1967).
(3) In ruminant, much of the dietary in organic $\mathrm{Se}$ was reduced to insoluble forms, such as elemental Se or selenides by ruminal micro-organisms, and most of the Se was excreted in the feces (Cousins et al., 1961). Highly significant correlation between blood Se level and blood GSH-Px activity has been reported in cattle (Pavlata et al., 2000 and Calamari et al., 2010).

The present results are in agreement with Qin et al. (2007) results, who reported that higher Se level and GSH-Px activity in the blood of lambs fed the diet supplemented with selenium yeast rather than sodium selenite. Similar effect was also found by Hassan et al. (2015) who found a significant increase in GSH-PX as Se-algae level that increased in the diet of rabbits. The interaction between the Se source and dietary Se level indicated that feed Se maintain erythrocyte GSH-Px activity better than inorganic Se when cows are depleted (Aspila, 1991). Pehrson et al. (1989) have demonstrated in heifers that organic Se increases erythrocyte GSH-Px activity more efficiently than inorganic Se. Generally, when dietary Se intake is low, the correlation between dietary Se and erythrocyte GSH-PX is poor (Whanger et al., 1977)

Table 4. Effect of different Se sources on plasma concentrations of IL-1 and IL-2 (ng/mL) in Lambs

\begin{tabular}{|c|c|c|c|c|}
\hline \multirow{2}{*}{ Month } & \multicolumn{4}{|c|}{ Plasma concentration of IL-1 } \\
\hline & Control & T1 & $\mathbf{T 2}$ & T3 \\
\hline At the beginning & $0.290 \pm 0.001$ & $0.295 \pm 0.003$ & $0.298 \pm 0.002$ & $0.290 \pm 0.002$ \\
\hline 1 & $0.275^{\mathrm{B}} \pm 0.005$ & $0.364^{\mathrm{A}} \pm 0.005$ & $0.367^{\mathrm{A}} \pm 0.008$ & $0.370^{\mathrm{A}} \pm 0.015$ \\
\hline 2 & $0.265^{\mathrm{B}} \pm 0.005$ & $0.409^{\mathrm{A}} \pm 0.003$ & $0.413^{\mathrm{A}} \pm 0.009$ & $0.416^{\mathrm{A}} \pm 0.009$ \\
\hline 3 & $0.257^{\mathrm{B}} \pm 0.005$ & $0.465^{\mathrm{A}} \pm 0.005$ & $0.468^{\mathrm{A}} \pm 0.019$ & $0.470^{\mathrm{A}} \pm 0.013$ \\
\hline 4 & $0.252^{\mathrm{B}} \pm 0.005$ & $0.552^{\mathrm{A}} \pm 0.021$ & $0.556^{\mathrm{A}} \pm 0.007$ & $0.558^{\mathrm{A}} \pm 0.005$ \\
\hline \multirow[t]{2}{*}{5} & $0.247^{\mathrm{B}} \pm 0.005$ & $0.581^{\mathrm{A}} \pm 0.003$ & $0.583^{\mathrm{A}} \pm 0.004$ & $0.588^{\mathrm{A}} \pm 0.002$ \\
\hline & \multicolumn{4}{|c|}{ Plasma concentration of IL-2 } \\
\hline At the beginning & $2.480 \pm 0.180$ & $2.416 \pm 0.173$ & $2.434 \pm 0.192$ & $2.436 \pm 0.132$ \\
\hline 1 & $2.017^{\mathrm{B}} \pm 0.244$ & $3.067^{\mathrm{A}} \pm 0.180$ & $3.097^{\mathrm{A}} \pm 0.022$ & $3.102^{\mathrm{A}} \pm 0.075$ \\
\hline 2 & $1.765^{\mathrm{B}} \pm 0.142$ & $3.473^{\mathrm{A}} \pm 0.208$ & $3.475^{\mathrm{A}} \pm 0.059$ & $3.479^{\mathrm{A}} \pm 0.147$ \\
\hline 3 & $1.570^{\mathrm{B}} \pm 0.116$ & $3.486^{\mathrm{A}} \pm 0.138$ & $3.695^{\mathrm{A}} \pm 0.174$ & $3.705^{\mathrm{A}} \pm 0.235$ \\
\hline 4 & $1.386^{\mathrm{B}} \pm 0.103$ & $3.675^{\mathrm{A}} \pm 0.049$ & $3.782^{\mathrm{A}} \pm 0.134$ & $3.787^{\mathrm{A}} \pm 0.051$ \\
\hline 5 & $1.209^{\mathrm{B}} \pm 0.096$ & $3.860^{\mathrm{A}} \pm 0.030$ & $3.881^{\mathrm{A}} \pm 0.124$ & $3.889^{\mathrm{A}} \pm 0.044$ \\
\hline
\end{tabular}

Control $=$ Without treatment;T1 $=$ Sodium selenite treatment; T2 $=$ Vitamin E and Selenium treatment; T3= Selenized yeast treatment. Means and Standard error (S.E) followed by different superscript letter within the same row are significantly different at $\mathrm{P}<0.01$

\section{C-Plasma concentrations of Interleukin-1 and Interleukin-2:}

The effect of different Se sources on plasma concentrations of Interleukin-1 (IL-1) and Interleukin-2 (IL-2) are presented in Table (4). There were no significant differences in plasma IL-1 and IL-2 concentrations among the experimental groups at the beginning of the experiment in comparison with the control group. Also, in control group the mean concentration of IL-1 in plasma gradually dropped from $0.290 \mathrm{ng} / \mathrm{mL}$ at the beginning to 0.247 $\mathrm{ng} / \mathrm{mL}$ at the end of the trail. The corresponding values for IL-2 were $2.480 \mathrm{ng} / \mathrm{mL}$ and $1.209 \mathrm{ng} / \mathrm{mL}$.
At one month of experimental period, concentrations of IL-1 and IL-2 in plasma of all the supplemented groups were significantly $(\mathrm{P}<0.01)$ higher than those

in the control one. The highest values of plasma IL-1 and IL-2 concentrations were recorded in T3 followed by $\mathrm{T} 2, \mathrm{~T} 1$ and the lowest values were recorded in the control group.

Interleukins play very important roles in animal immune function (Grimble, 1998). Ru-duan et al. (1992) showed that $\mathrm{Se}$ was able to increase the production of IL-1 by macrophages and IL-2 by lymphocytes in the presence of lectin. Also, Johnson 
et al. (2000) reported that sodium selenite increased the production of IL-1 in lipopolysaccharide that stimulated splenic macrophages. Similarly, Safir et al. (2003) observed that secretion of IL-1 from J774.1 macrophages exposed to $10 \mu \mathrm{g} / \mathrm{mL}$ liposaccharide that was enhanced upon $\mathrm{Se}$ supplementation. Moreover, Brown et al. (1985) reported that $\mathrm{Se}$ at $10 \mathrm{ng} / \mathrm{mL}$ enhanced IL-2 production nearly two fold from a primate lymphoid cell line in serum-free media. The amounts of IL-2 and IL-1 produced by lymphocytes and macrophages, removed from Se-deficient or Se-supplemented animals did not differ significantly (KiremidjianSchumacher et al. 1990). Koller et al. (1986) also indicated that the activity of IL-1 produced by macrophages was unaffected by Se exposure. The results of our study indicated that supplementation of Se in the lamb's diet improved IL-1 and IL-2 levels in plasma. Moreover, there were no significant differences for IL-1 and IL-2 levels in plasma of lambs supplemented with organic or inorganic Se source.

These results are in agreement with those of Qin et al. (2007) who found that there are no significant differences for IL-1 and IL-2 levels in lambs supplemented with organic or inorganic Se. Further studies are needed to document the mechanisms of Se regulating the plasma IL-1 and IL-2 levels in vivo and to explain why there are no significant differences for IL-1 and IL-2 levels in lambs supplemented with organic or inorganic Se. Generally, levels of Se and Vit. E above the generally accepted requirements enhances the immune response in several species. Both Vit. E and Se protect leukocytes and macrophage during phagocytosis, the mechanism by which mammals immunologically kill invading bacteria (McDowell, 1992).

\section{CONCLUSIONS}

From these findings could be concluded that the supplementation of Selenium in the ration especially in the selenized yeast form led to improve the productive performance and physiological responses as a result of positive effect on glutathione peroxidase (GSH-Px) and interleukins (IL-1\& IL-2) concentrations and consequently improved immune responses of lambs.

Also, form these results could be noted that the using selenium as antioxidant improved immune responses and metabolizable efficiency. Therefore, the results recommended to using selenized yeast form in the lamb rations especially for small farmers and holders under Upper Egypt conditions.

\section{REFERENCES}

A.O.A.C., 2000. Official Methods of Analysis, $15^{\text {th }}$ edn. Association of Official Analytical Chemists, Arlington, VA, USA.
Antunović, Z., J. Novoselec, M. Šperanda, T. Klapec, S. Ćavar, B. Mioč, and R. Vuković, 2014. Influence of dietary supplementation with Selenium on blood metabolic profile and thyroid hormones activities in fattening lambs. Pakistan Veterinary Journal, 34:224-228.

Aspila, P., 1991. Metabolism of selenite, selenomethionine and feed-incorporated selenium in lactating goats and dairy cows. J. Agric. Sci. Finland 63:1-74.

Awad, J. A., J. D. Morrow, K. E. Hill, L. J. Roberts, and R. F. Burk, 1994. Detection and localization of lipid peroxidation in Selenium-and vitamin Edeficient rats using F2-isoprostanes. The Journal of Nutrition, 124:810-816.

Awadeh, F. T., R. L. Kincaid, and K. A. Johnson, 1998. Effect of level and source of dietary Selenium on concentrations of thyroid hormones and immunoglobulins in beef cows and calves. Journal of Animal Science, 76: 1204-1215.

Brown, R. L., R. L. Griffith, F. W. Ruscetti, and H. Rabin, 1985. Modulation of interleukin 2 release from a primate lymphoid cell line in serum-free and serum-containing media. Cellular Immunology, 92: 14-21.

Calamari, L. U. I. G. I., F. Petrera, and G. Bertin, 2010. Effects of either sodium selenite or Se yeast (Sc CNCM I-3060) supplementation on Selenium status and milk characteristics in dairy cows. Livestock Science, 128: 154-165.

Cantor, A. H., P. D. Moorehead, and M. A. Musser, 1982. Comparative effects of sodium selenite and selenomethionine upon nutrition muscular dystrophy, selenium-dependent glutathione peroxidase, and tissue selenium concentrations of turkey. Poults Poultry Science 61:478-484.

Cousins, F. B., and I. M. Cairney, 1961. Some aspects of Selenium metabolism in sheep. Crop and Pasture Science, 12: 927-943.

Ehlig, C. F., D. E. Hogue, W. H. Allaway, and D. J. Hamm, 1967. Fate of Selenium from selenite or selenomethionine with or without vitamin $E$ in lambs. The Journal of Nutrition, 92: 121-126.

Ganther, H. E., O. A., Levander, and C. A. , Baumann, 1966. Dietary control of Selenium volatilization in the rat. The Journal of Nutrition, 88: 55-60.

Grace, N. D., and S. O. Knowles, 2002. A reference curve using blood Selenium concentration to diagnose Selenium deficiency and predict growth responses in lambs. New Zealand Veterinary Journal, 50: 163-165.

Gresakova, L., K. Cobanova, and S. Faix, 2013. Selenium retention in lambs fed diets supplemented with Selenium from inorganic or organic sources. Small Ruminant Research, 111: 76-82.

Grimble, R. F., 1998. Modification of inflammatory aspects of immune function by nutrients. Nutrition Research, 18: 1297-1317. 
Gunter, S. A., P. A. Beck, and J. M. Phillips, 2003. Effects of supplementary selenium source on the performance and blood measurements in beef cows and their calves. Journal of Animal Science, 81: 856-864.

Hassan, F. A., E. M. Hoballah, M. M. Basyony, and Sh. A. El-Medany, 2015. Effect of dietary selenium enriched micro-algae supplementation on growth performance and anti-oxidative status of rabbits under high ambient temperature in summer season. Egyptian Journal of Nutrition and Feeds, 18 (2): 131-146.

Heider, J., and A. Bock, 1993. Selenium metabolism in micro-organisms. Advances in Microbial Physiology, 35: 71-109.

Huang, K., and S. Yang, 2002. Inhibitory effect of Selenium on Cryptosporidium parvum infection in vitro and in vivo. Biological Trace Element Research, 90(1-3): 261-272.

Johnson, V. J., M. Tsunoda, and R. P. Sharma, 2000. Increased production of proinflammatory cytokines by murine macrophages following oral exposure to sodium selenite but not to seleno-Lmethionine. Archives of Environmental Contamination and Toxicology, 39: 243-250.

Juniper, D. T., R. H. Phipps, E. Ramos-Morales, and G. Bertin, 2009. Effects of dietary supplementation with Selenium enriched yeast or sodium selenite on Selenium tissue distribution and meat quality in lambs. Animal Feed Science and Technology, 149:228-239.

Kholif, A.M., and S.M. Kholif, 2008. Effect of selenium enriched yeast supplementation on the productive performance of lactating buffaloes. Egyptian Journal of Nutrition and Feeds, 11: 187200.

Kiremidjian-Schumacher, L., M. Roy, H. I. Wishe, M. W. Cohen, and G. Stotzky, 1990. Selenium and immune cell functions. I. Effect on lymphocyte proliferation and production of interleukin 1 and interleukin 2. Experimental Biology and Medicine, 193: 136-142.

Knowles, S. O., N. D. Grace, K. Wurms, and J. Lee, 1999. Significance of amount and form of dietary Selenium on blood, milk, and casein Selenium concentrations in grazing cows. Journal of Dairy Science, 82:429-437.

Koenig, K. M., L. M. Rode, R. D. Cohen, and W. T. Buckley, 1997. Effects of diet and chemical form of Selenium on Selenium metabolism in sheep. Journal of Animal Science, 75: 817-827.

Koller, L. D., J. H. Exon, P. A. Talcott, C. A. Osborne, and G. M. Henningsen, 1986. Immune responses in rats supplemented with Selenium. Clinical and Experimental Immunology, 63: 570.

Kumar, N., A. K. Garg, R. S. Dass, V. K. Chaturvedi, V. Mudgal, and V. P. Varshney, 2009. Selenium supplementation influences growth performance, antioxidant status and immune response in lambs. Animal Feed Science and Technology, 153: 7787.
Levander, O. A., A. L. Ager, and M. A. Beck,1995. Vitamin $\mathrm{E}$ and Selenium: contrasting and interacting nutritional determinants of host resistance to parasitic and viral infections. Proceedings of the Nutrition Society, 54: 475-487.

Lopez, P. L., R. L. Preston, and W.H. P fander, 1968. Whole body retention, tissue distribution and excretion of Selenium-75 after oral and intravenous administration in lambs fed varying Selenium intakes. The Journal of Nutrition, 97:123 -132.

McDowell, L. R., 1992. Minerals in Animal and Human Nutrition. Academic Press, Inc, San Diego.

McKenzie, R. C., T. S. Rafferty, and G. J. Beckett, 1998. Selenium: an essential element for immune function. Immunology Today, 19: 342-345.

Mudgal, V., A. K. Garg, and R. S. Dass, 2007. Effect of dietary Selenium and copper supplementation on growth and nutrient utilization in buffalo (Bubalus bubalis) calves. Animal Nutrition and Feed Technology, 7: 79-88.

National Research Council (NRC), 1985. Nutrient Requirement of Sheep. $6^{\text {th }}$ ed. National Academy Press, Washington, DC, USA.

National Research Council (NRC), 2007. Nutrient Requirements of Small Ruminants: Sheep, Goats, Cervids, and New World Camelids. Committee on Nutrient Requirements of Small Ruminants. National Academy Press, Washington, DC, USA.

Nicholson, J. W. G., R. E. McQueen, and R. S. Bush, 1991. Response of growing cattle to supplementation with organically bound or inorganic sources of Selenium or yeast cultures. Canadian Journal of Animal Science, 71: 803811.

Norheim, G., and A. Haugen, 1986. Precise determination of Selenium in tissues using automated wet digestion and an automated hydride generator - atomic absorption spectroscopy system. Acta Pharmacol Toxicol, 59: 610-612.

Ortman, K., and B. Pehrson, 1997. Selenite and Selenium yeast as feed supplements for dairy cows. Journal of Veterinary Medicine Series A, 44: 373-380.

Pavlata, L., A. Pechova, and J. Illek, 2000. Direct and Indirect Assessment of Selenium status in cattleA comparison. Acta Veterinaria Brno, 69: 281290.

Pehrson, B., M. Knutsson, and M. Gyllenswärd, 1989. Glutathione peroxidase activity in heifers fed diets supplemented with organic and inorganic Selenium compounds. Swedish Journal of Agricultural Research.

Petersen, R.G., 1985. Design and analysis of experiments. Marcel Dekker, Inc., New York, USA.

Petrera, F., L. U. I. G. I. Calamari, and G. Bertin, 2009. Effect of either sodium selenite or Se-yeast supplementation on Selenium status and milk 
characteristics in dairy goats. Small Ruminant Research, 82: 130-138.

Qin, S., J. Gao, and K. Huang, 2007. Effects of different Selenium sources on tissue Selenium concentrations, blood GSH-Px activities and plasma interleukin levels in finishing lambs. Biological Trace Element Research, 116: 91-102.

Rock, M. J., R. L. Kincaid, and G. E. Carstens, 2001. Effects of prenatal source and level of dietary Selenium on passive immunity and thermometabolism of newborn lambs. Small Ruminant Research, 40:129-138.

Ru-duan, W., W. Chang-sen, F. Zuo-hua, and L. Yi, 1992. Investigation on the effect of Selenium on $\mathrm{T}$ lymphocyte proliferation and its mechanisms. Journal of Tongji Medical University, 12: 33-38.

Ružić-Muslić, D., M. P Petrović, V. Caro-Petrović, M. M. Petrović, Z. Bijelić, Z. Ilić and J. Stojković, 2014. Effects of adding different forms of Selenium in diets for fattening lambs. Biotechnology in Animal Husbandry, 30(4):589600.

Safir, N., A. Wendel, R. Saile, and L. Chabraoui, 2003. The effect of Selenium on immune functions of J774. 1 cells. Clinical chemistry and Laboratory Medicine, 41: 1005-1011.

Sankari, S., 1985. Plasma glutathione peroxidase and tissue selenium response to selenium supplementation in swine. Acta Veterinary Scand. Suppl. 81:1 1-20

SAS., 2008. SAS User ś guide: Statistics, SAS Institute Inc., Cary, NC.

Shi, L., W. Xun, W. Yue, C. Zhang, Y. Ren, L. Shi, and F. Lei, 2011. Effect of sodium selenite, Seyeast and nano-elemental Selenium on growth performance, Se concentration and antioxidant status in growing male goats. Small Ruminant Research, 96: 49-52.

Swanson, C. A., B. H. Patterson, O. A. Levander, C. Veillon, P. R. Taylor, K. Helzlsouer, and L. A. Zech, 1991. Human [74Se] selenomethionine metabolism: a kinetic model. The American Journal of Clinical Nutrition, 54: 917-926.

Van Ryssen, J. B., J. T. Deagen, M. A. Beilstein, and P. D. Whanger, 1989. Comparative metabolism of organic and inorganic Selenium by sheep. Journal of Agricultural and Food Chemistry, 37: 13581363.

Vignola, G., L. Lambertini, G. Mazzone, M. Giammarco, M. Tassinari, G. Martelli, and G. Bertin, 2009. Effects of Selenium source and level of supplementation on the performance and meat quality of lambs. Meat Science, 81: 678685.

Wang, Y. B, and B. H. Xu, 2008. Effect of different Selenium sources (sodium selenite and Selenium yeast) on broiler chickens. Animal Feed Science and Technology, 144: 306-314.

Weiss, W.P., 2003. Selenium nutrition of dairy cows: comparing responses to organic and inorganic Selenium forms. In: Proc. Alltech's $19^{\text {th }}$ ann Symp, Nutritional Biotechnology in the Feed and Food Industries, Ed, T.P. Lyons and K.A. Jacques, Nottingham University Press. UK: pp. 333-343.

Whanger, P.D., P.H. Weswig, J.A. Schmitz, and J.E. Oldfield, 1977. Effects of selenium and vitamin E on blood Selenium levels, tissue glutathione peroxidase activities and white muscle disease in sheep fed purified or hay diets. Journal of Nutrition. 107(7):1298-1307.

Wichtel, J. J., A. L. Craigie, H. Varela-Alvarez, and N. B. Williamson, 1994. The effect of intraruminal Selenium pellets on growth rate, lactation and reproductive efficiency in dairy cattle. New Zealand Veterinary Journal, 42: 205-210.

Yue, W., C. Zhang, L. Shi, Y. Ren, Y. Jiang, and D. O. Kleemann, 2009. Effect of supplemental selenomethionine on growth performance and serum antioxidant status in Taihang Black goats. Asian-Aust Journal of Animal Science, 22: 365370. 
أداء النمو والاستجابة المناعية للحملان متأثرة بإضافة مصادر مختلفة من السيلينيوم فى العليقة

$$
\text { جمال محمود سلومة'، جلال عبد المطلب عبد الحافظ'، أيمن يوسف كساب"، على سليم على' }
$$

ا ـ قسم الإنتاج الحيواني كلية الزراعة جامعة سوهاج، r ـ ـ قسم الإنتاج الحيواني كلية الزراعة جامعة أسيوط، بـ ـ قسم الإنتاج الحيواني كلية الزراعة جامعة أسيوط (فُرع الوادي الجدايد)

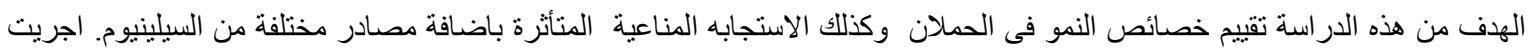

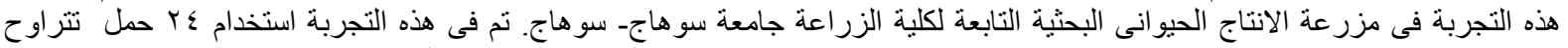

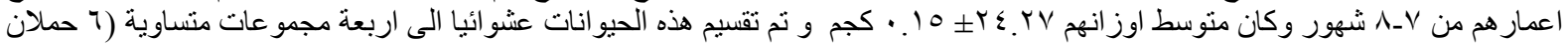

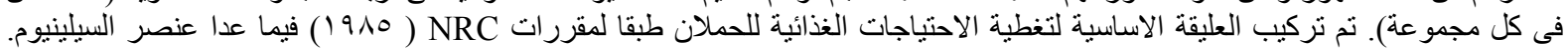

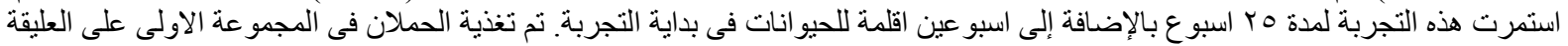

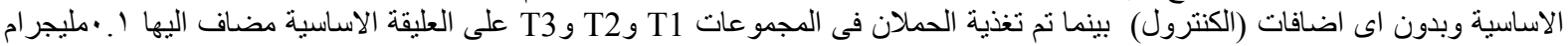

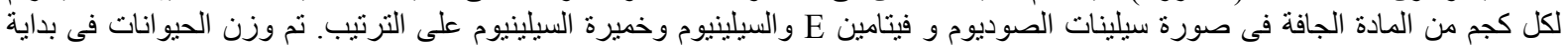

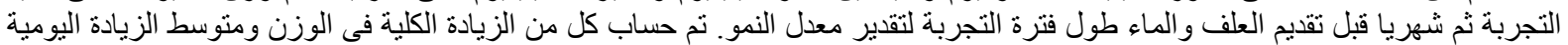

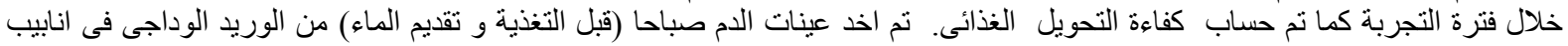

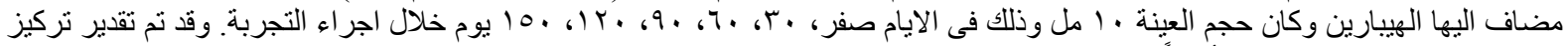

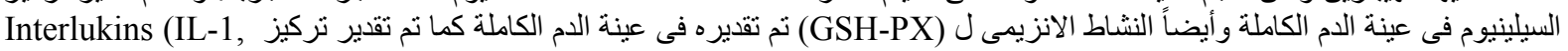

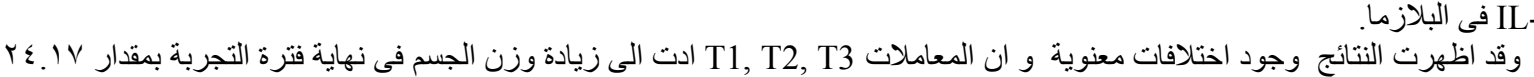

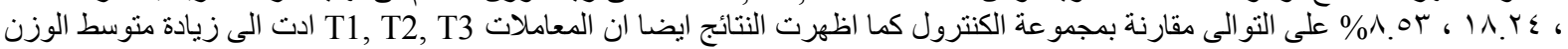

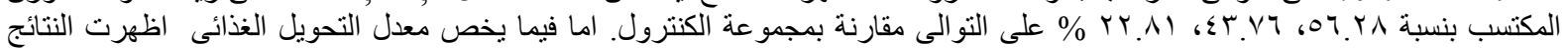

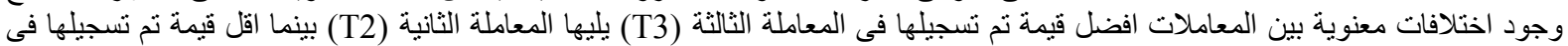

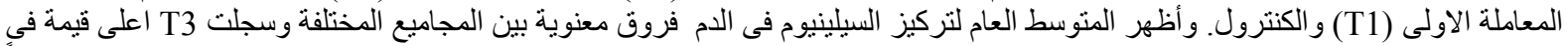

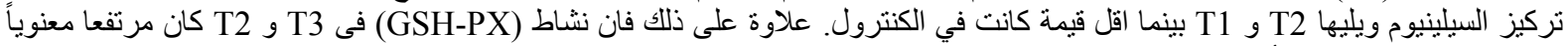

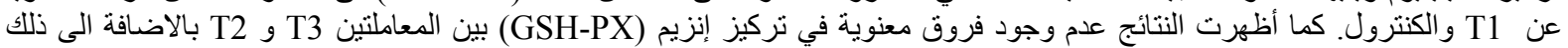

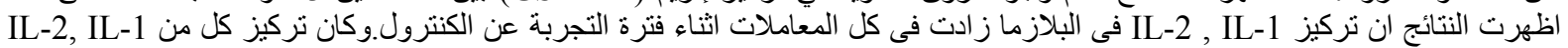

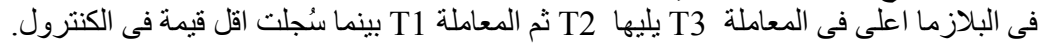

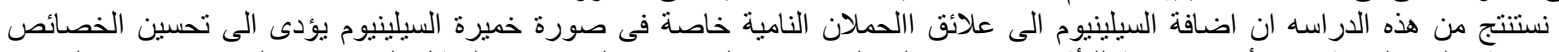

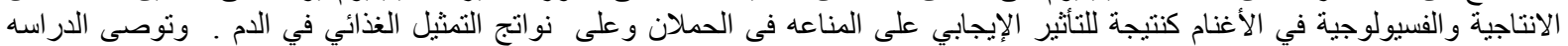

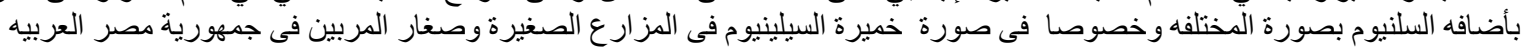

